\title{
Prioritizing new elements with a brief preview period: Evidence against visual marking
}

\author{
MIEKE DONK and ROEL C. VERBURG \\ Vrije Universiteit, Amsterdam, The Netherlands
}

\begin{abstract}
Watson and Humphreys (1997) have proposed that the ability to prioritize new elements over old elements involves a time-consuming process (of at least $400 \mathrm{msec}$ ) of active inhibition of the locations of the old elements, which they referred to as visual marking. Recently, Donk and Theeuwes (2001) have suggested that prioritized selection of new over old elements is an instantaneous process related to the luminance change accompanying the appearance of the new elements. The aim of the present study was to test these two alternatives by investigating whether prioritized selection of new over old elements could be achieved with a very short preview of the old elements $(50 \mathrm{msec})$. The results indicated that participants were able to prioritize selection of new over old elements when the new elements were presented with luminance onset whereas the old elements were not. New elements could not be prioritized if both the old and the new elements appeared with luminance onset. The results indicated that prioritization of new elements is based on an instantaneous process, rather than on a time-consuming process.
\end{abstract}

Watson and Humphreys (1997) have proposed that people have a mechanism for prioritizing the selection of new events or objects over old ones. This mechanism, referred to as visual marking (see also Theeuwes, Kramer, \& Atchley, 1998; Watson \& Humphreys, 1997), is assumed to operate through top-down attentional inhibition applied to the positions of old stimuli. Evidence for the ability to prioritize new over old elements stems from experiments in which the preview paradigm has been used. Thus, Watson and Humphreys set up three conditions: a conjunction search task, in which participants had to detect a blue letter $H$ target between green $H$ s and blue $A$ s; a feature search task, which was essentially the same as the conjunction search task, except that no green distractors were presented (therefore, the display size was half that of the conjunction search task); and a preview condition, in which first the green $H$ s (i.e., the old elements) were presented and, after $1,000 \mathrm{msec}$, the blue $A \mathrm{~s}$ were added to the display, with or without the blue $H$ target (i.e., the new elements). Watson and Humphreys found that slopes in the preview condition were identical to those obtained in the feature search condition and different from those obtained in the conjunction search condition. This difference between the slopes obtained in the preview condition and those obtained in the conjunction search condition, denoted as the preview effect, was taken

We thank Glyn Humphreys, Tram Neill, Jay Pratt, Jan Theeuwes, and one anonymous reviewer for their helpful comments on an earlier version of this article. Correspondence concerning this article should be addressed to M. Donk, Department of Cognitive Psychology, Vrije Universiteit, van der Boechorststraat 1, 1081 BT Amsterdam, The Netherlands (e-mail: w.donk@psy.vu.nl). as evidence that, with a preview, observers can prioritize the selection of new over old elements.

Even though the preview effect indeed shows that observers are able to prioritize the selection of new over old elements, it is unclear whether this ability truly is the result of a process in which the old elements are deprioritized during the preview, as was suggested by Watson and Humphreys (1997). Alternatively, it might be that new elements can be directly prioritized due to the sudden luminance onset accompanying their appearance (Yantis \& Jonides, 1984). Indeed, Donk and Theeuwes (2001) have shown that if new elements appear without luminance change (e.g., if the elements are equiluminant with the background), the new elements can no longer be prioritized, suggesting that prioritized selection might not be due to top-down inhibition of old objects, as was suggested by Watson and Humphreys. Possibly, observers are able to directly prioritize the selection of new elements by the luminance onsets accompanying their appearance (see also Donk \& Theeuwes, 2003).

Both an inhibition account, as proposed by Watson and Humphreys (1997), and an onset account, as advocated by Donk and Theeuwes (2001), can explain the preview effect. Nevertheless, these explanationsdiffer fundamentally from each other. Whereas an inhibition account assumes that observers are involved in an active process of inhibiting the locations of the old elements during the preview, the onset account basically presumes no observer involvement prior to the appearance of the new elements. In fact, prioritized selection is assumed to occur instantaneously at the moment the new elements appear. To date, there is not much direct evidence for or against the idea that observers are actively involved in inhibiting the old elements prior to the appearance of new elements. One exception is Experi- 
ment 3 of Watson and Humphreys. In this experiment, they showed that if the preview period was too short - that is, below $400 \mathrm{msec}$ - no prioritized selection was obtained. In other words, for prioritized selection to occur, a minimal interval of $400 \mathrm{msec}$ was required between the appearances of old and new elements. Watson and Humphreys interpreted these results as evidence for their inhibition account. For inhibition to take its effect, a minimal interval of $400 \mathrm{msec}$ is required, because the application of inhibition is a time-consuming process. They point out that if no observer involvement is required prior to the presentation of new elements, it is hard to understand why the duration of the preview period would matter.

Even though it is clear that the requirement for a minimal time interval is in line with an inhibition account (Watson \& Humphreys, 1997), it is feasible that a minimal time interval is also required for an onset account (Donk $\&$ Theeuwes, 2001). Abrupt luminance onsets may cease to attract attention when they are preceded by other luminance onsets. Typically, in the preview paradigm, onsets of new elements are preceded by onsets of old elements. To allow new elements to gain prioritized selection through their luminance onset, it is possible that a minimal interval between the appearances of old and new elements is necessary. There are several studies suggesting that if attention is directed to some location in the visual field, visual luminance onsets elsewhere cease to attract attention (Theeuwes, 1991; Yantis \& Jonides, 1990). It is possible that something similar occurs with short intervals within the preview paradigm. If multiple old elements appear with luminance onset, attention might be captured. It might take a certain time interval before attention can be completely disengaged from the locations of the old elements (Duncan, Ward, \& Shapiro, 1994). As a consequence, new elements may not be capable of capturing attention when they are presented within this interval.

The aim of the present study was to test this alternative. We used the preview paradigm, in which observers searched for a target that could occur only among the new elements. In one condition, the equiluminant preview condition, a variable number of old elements was presented equiluminant with the background, followed after $50 \mathrm{msec}$ by the addition of a variable number of new elements. The new elements were presented with luminance onset; that is, the luminance of the new elements was initially higher than that of the background. After $50 \mathrm{msec}$, the luminance of the new elements was decreased to the luminance level of the background and that of the old elements. In the other condition, the increased luminance preview condition, both the old and the new elements appeared with an initial luminance onset of $50 \mathrm{msec}$. If prioritized selection occurs through a time-consuming application of top-down inhibition to the locations of old elements, it was predicted that prioritizing would not occur in the present experiment. If, however, prioritized selection is related to the luminance onsets accompanying the appearance of new elements, prioritized selection should occur in the equiluminant preview condition, but not in the increased luminance preview condition.

\section{METHOD}

\section{Participants}

Twelve participants (4 females and 8 males), 19 to 28 years of age, took part in the present experiment.

\section{Task and Stimuli}

The task of the participants was to indicate the presence or absence of a prespecified target (the capital letter $H$ ) between multiple nontargets (the letters $A, B, C, E, F, G, J, K, M, N, P, R, S, T, U$, and $V$ ). The target was presented in $50 \%$ of the trials. If the target was present, it was presented among the new elements. In the equiluminant preview condition, the participants were presented with a white central fixation cross on a gray background (CIE $x, y$ chromaticity coordinates of .277 and $\left..310,10.2 \mathrm{~cd} / \mathrm{m}^{2}\right)$. After 2,000 msec, 5, 10, or 15 green letters (old elements; CIE $x, y$ chromaticity coordinates of .293 and $.600,11.9 \mathrm{~cd} / \mathrm{m}^{2}$ ) were presented on the display equiluminant with the background, as determined by a flicker-fusion test at the center of the screen. After $50 \mathrm{msec}, 5,10$, or 15 letters (new elements) were added to the display, appearing in light green (CIE $x, y$ chromaticity coordinates of .288 and $.605,31.3 \mathrm{~cd} / \mathrm{m}^{2}$ ). After another $50 \mathrm{msec}$, the luminance of the new elements returned to that of the old elements, making them indistinguishable from the old elements. In the increased luminance preview condition, both the old and the new elements were presented with an initial luminance increase upon appearance. Furthermore, the increased luminance preview condition was identical to the equiluminant preview condition (see Figure 1). The old and the new elements were presented randomly in an area subtending $24.2^{\circ} \times 20.1^{\circ}$ of visual angle at an observation distance of $60 \mathrm{~cm}$. The letters were approximately $10 \mathrm{~mm}$ wide and $18 \mathrm{~mm}$ high.

\section{Apparatus}

Stimuli were presented on a 19-in. Multiscan color monitor (with an ATI Rage 4-Mb card), which was controlled by a Celeron 400MHz/128-Mb PC. The response keys were the "z" key and the "/" key on the computer keyboard.

\section{Design and Procedure}

The experiment consisted of two blocks of trials corresponding to the equiluminant preview condition and the increased luminance preview condition. Each participant was tested in both conditions. Each block of trials consisted of 36 practice trials, followed by 432 experimental trials. Number of old elements $(5,10$, and 15$)$, number of new elements $(5,10$, and 15), and target presence (target present and target absent) were randomly varied within blocks of trials.

Each trial started with a white fixation cross, after which the old elements were shown. Fifty milliseconds later, the new elements were presented. When the participants responded incorrectly, a tone was presented. After each 36 trials, the participants received feedback about their performance in terms of the percentage of incorrect responses and the average response time (RT). The sequence of conditions was counterbalanced over participants. Half of the participants were instructed to press the " $\mathrm{z}$ " key when the target was present and the "/" key when the target was absent. The other half of the participants were instructed to do the opposite. The participants were instructed to respond as quickly and accurately as possible. They were familiar with the fact that if the target was present, it was presented among the new elements.

\section{RESULTS}

Mean correct RTs and percentages of errors were calculated for each participant. One participant had an exceptionally high mean RT (1,613 msec), and another had a very high percentage of errors (18\%). These two participants were excluded from further analyses. 


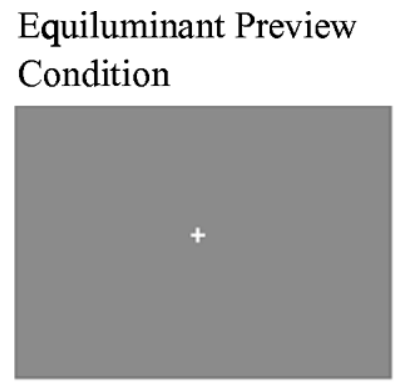

$2,000 \mathrm{msec}$

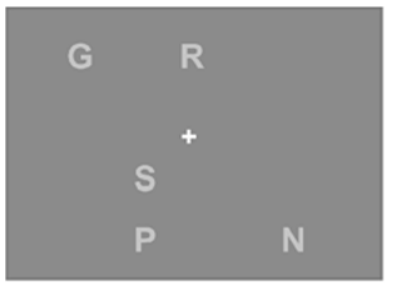

$50 \mathrm{msec}$

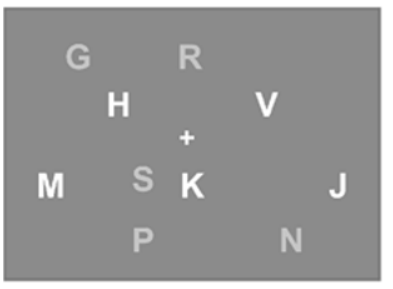

$50 \mathrm{msec}$

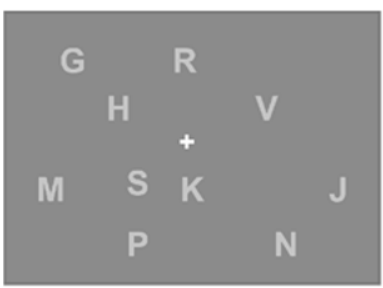

until response
Increased Luminance

Preview Condition

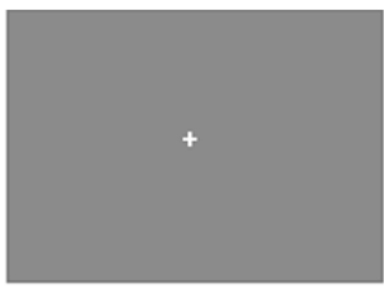

$2,000 \mathrm{msec}$

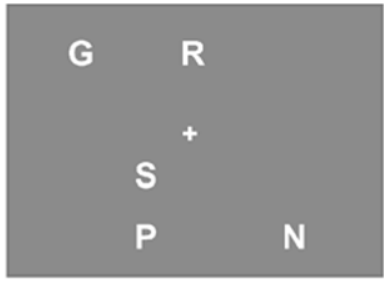

$50 \mathrm{msec}$

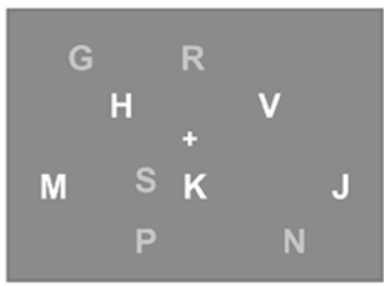

$50 \mathrm{msec}$

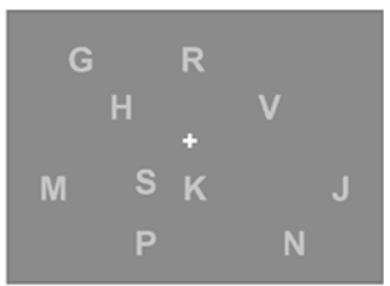

until response

Figure 1. Examples of the sequential events in the trials of the equiluminant preview and the increased luminance preview conditions. Dark gray corresponds to gray, light gray corresponds to green, and white corresponds to light green in the experiment. Note that the light gray letters in the figure are green in the experiment and equiluminant to the gray background.

Figure 2 shows the mean correct RTs over the remaining 10 participants as a function of condition (equiluminant preview vs. increased luminance preview), number of old elements $(5,10$, or 15$)$, number of new elements $(5,10$, or 15$)$, and target presence (target present vs. target absent). Generally, RTs were larger for target-absent trials than for target-present trials $[F(1,9)=68.54, p<.01]$.

An analysis of variance (ANOVA) was conducted on the individual correct RTs of the target-present trials only, with condition (equiluminant preview vs. increased luminance preview), number of old elements $(5,10$, or 15$)$, and number of new elements $(5,10$, or 15$)$ as repeated measures factors. There were statistically significant main effects of number of old elements $[F(2,18)=18.32$, $p<.01]$ and number of new elements $[F(2,18)=37.20$, $p<.01]$. Furthermore, there was a significant interaction between condition and number of old elements $[F(2,18)=$ $5.56, p<.02]$, implying that the number of old elements affected RT differently in the equiluminant preview condition than in the increased luminance preview condition. In the equiluminant preview condition, RT was unaffected by the number of old elements $[F(2,18)=3.39, p>.05]$, 


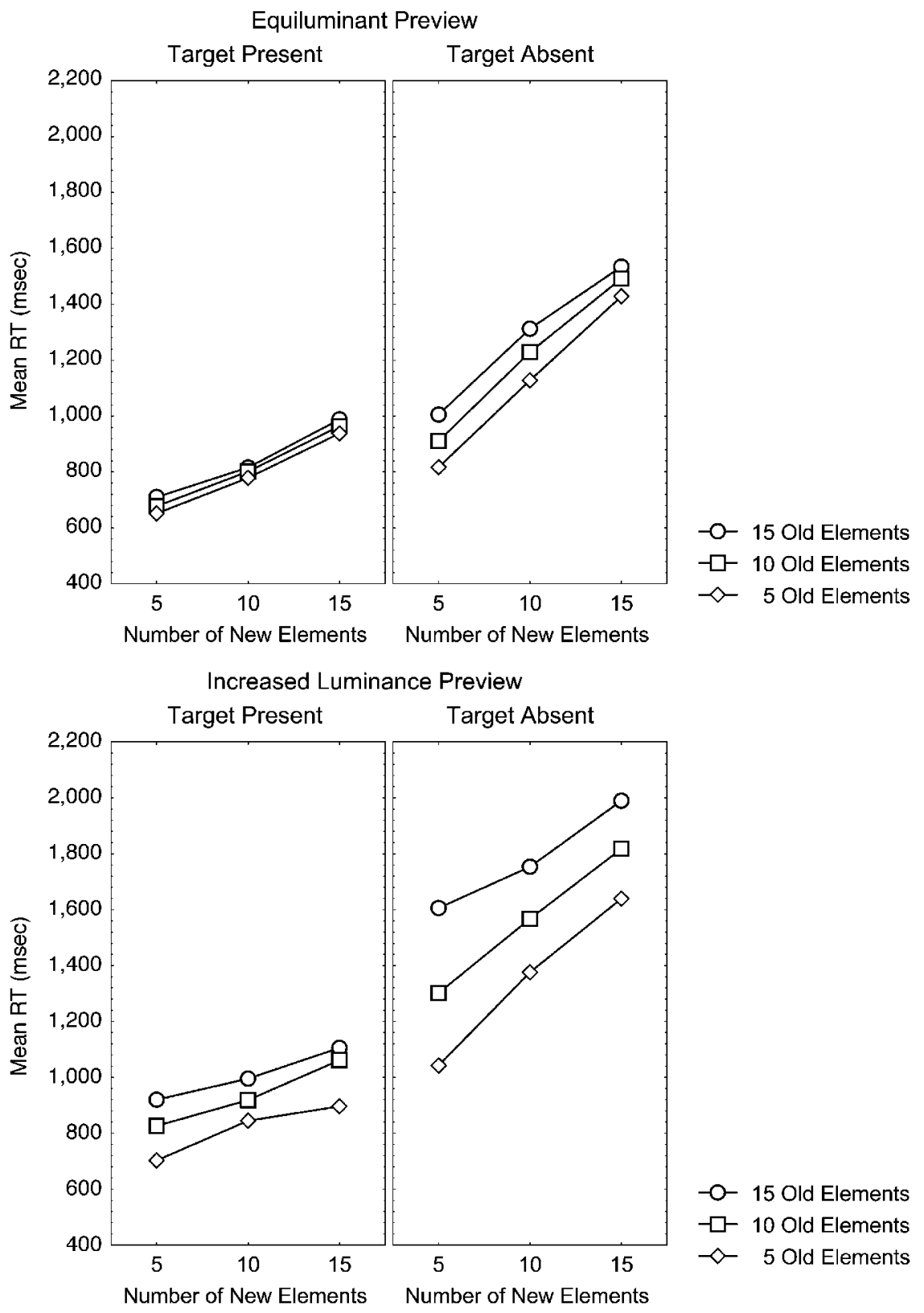

Figure 2. Mean reaction time (RT) as a function of target presence, number of old elements, and number of new elements separately for the equiluminant preview and the increased luminance preview conditions.

whereas in the increased luminance preview condition, RT increased with the number of old elements $[F(2,18)=$ $13.33, p<.01]$.

To investigate whether the speed of search was equal through the old elements and the new elements, best-fitting lines were determined for the functions relating RT to the number of old elements and those relating RT to the number of new elements separately for each participant (see also Donk \& Theeuwes, 2001). Table 1 shows the mean search slopes and intercepts for target-present and target-absent trials in the equiluminant preview condition and the increased luminance preview condition. Generally, search slopes were larger for target-absent trials than for target-present trials $[F(1,9)=37.90, p<$ .01]. An ANOVA on the data for the target-present trials revealed only that in the equiluminant preview condition, the slopes of the functions relating RT to the number of old elements were smaller than the slopes of the functions 
Table 1

Mean Intercepts, Search Slopes, and Absent/Present Ratios Separately for the Functions Relating Reaction Time (RT) to the Number of Old Elements and Those Relating RT to the Number of New Elements

\begin{tabular}{|c|c|c|c|c|c|}
\hline \multirow[b]{2}{*}{ Condition } & \multicolumn{2}{|c|}{ Intercepts (msec) } & \multicolumn{3}{|c|}{ Slopes (msec/item) } \\
\hline & $\begin{array}{c}\text { Target-Present } \\
\text { Trials }\end{array}$ & $\begin{array}{c}\text { Target-Absent } \\
\text { Trials }\end{array}$ & $\begin{array}{c}\text { Target-Present } \\
\text { Trials }\end{array}$ & $\begin{array}{c}\text { Target-Absent } \\
\text { Trials }\end{array}$ & $\begin{array}{c}\text { Absent/Present } \\
\text { Ratio }\end{array}$ \\
\hline \multicolumn{6}{|l|}{ Equiluminant preview } \\
\hline Old elements & 758 & 1,048 & 5.2 & 15.8 & 3.0 \\
\hline New elements & 531 & 633 & 28.3 & 57.3 & 2.0 \\
\hline \multicolumn{6}{|c|}{ Increased luminance preview } \\
\hline Old elements & 725 & 1,134 & 19.2 & 43.1 & 2.2 \\
\hline New elements & 712 & 1,065 & 20.6 & 50.0 & 2.4 \\
\hline
\end{tabular}

relating $\mathrm{RT}$ to the number of new elements $[F(1,9)=$ $14.56, p<.01]$. This was not the case in the increased luminance preview condition $[F(1,9)=0.20]$.

The intercepts of the functions were larger for targetabsent trials than for target-present trials $[F(1,9)=45.74$, $p<.01]$. An ANOVA on the data for the target-present trials revealed only that in the equiluminant preview condition, the intercepts of the functions relating RT to the number of old elements were larger than the intercepts of the functions relating RT to the number of new elements $[F(1,9)=14.34, p<.01]$. This was not the case in the increased luminance preview condition $[F(1,9)=0.18]$.

Table 2 shows the average proportions of errors per condition. Error scores were affected by target presence $[F(1,9)=45.85, p<.01]$ : The participants were more inclined to respond target absent when the target was present than to respond target present when the target was absent. A separate ANOVA on the target-present trials revealed a main effect of number of new elements $[F(2,18)=11.90, p<.01]$ and an interaction between condition and number of new elements $[F(2,18)=4.98$, $p<.02]$. Error scores increased with the number of new elements. Furthermore, this increase developed differently in the two conditions.

\section{DISCUSSION}

The present study demonstrates that a brief preview interval (of $50 \mathrm{msec}$ ) prevents observers from prioritiz- ing selection of new over old elements only if both the old and the new elements appear with luminance onset. If old elements are presented without luminance onset, new elements can be perfectly prioritized for selection, as is evident from the finding that RT was completely unaffected by the number of old elements in the equiluminant preview condition. These findings provide strong evidence against the claim that prioritized selection is the result of a time-consuming process, as has been proposed by Watson and Humphreys (1997).

Watson and Humphreys's (1997) original account for the preview effect was (among other things) based on the finding that a full preview effect could be attained only if the old elements appear for around $400 \mathrm{msec}$ or more prior to the new elements. Recently, Humphreys et al. (2004) also showed that the efficiency of search increased nonlinearly as a function of the length of the preview period. The authors concluded that old elements need to precede new elements by at least $600 \mathrm{msec}$, because observers require some time to actively establish and inhibit a representation of the old elements. Accordingly, they assumed that with shorter preview periods, no full preview effect can be obtained, because of the inability of observers to consolidate and inhibit the representations of the old elements in time-that is, prior to the appearance of the new elements.

These conclusions are at odds with the present findings. If prioritized selection is the result of a time-consuming process of inhibiting the representation of old elements,

Table 2

Error Percentages Separately for Each Condition

\begin{tabular}{|c|c|c|c|c|c|c|}
\hline \multirow[b]{3}{*}{$\begin{array}{l}\text { Number } \\
\text { of New } \\
\text { Elements }\end{array}$} & \multicolumn{6}{|c|}{ Number of Old Elements } \\
\hline & \multicolumn{2}{|c|}{5} & \multicolumn{2}{|c|}{10} & \multicolumn{2}{|c|}{15} \\
\hline & $\begin{array}{c}\text { Equiluminant } \\
\text { Preview }\end{array}$ & $\begin{array}{c}\text { Increased } \\
\text { Luminance } \\
\text { Preview } \\
\end{array}$ & $\begin{array}{c}\text { Equiluminant } \\
\text { Preview }\end{array}$ & $\begin{array}{c}\text { Increased } \\
\text { Luminance } \\
\text { Preview } \\
\end{array}$ & $\begin{array}{c}\text { Equiluminant } \\
\text { Preview }\end{array}$ & $\begin{array}{c}\text { Increased } \\
\text { Luminance } \\
\text { Preview } \\
\end{array}$ \\
\hline \multicolumn{7}{|c|}{ Target Present Trials } \\
\hline $\begin{array}{r}5 \\
10 \\
15\end{array}$ & $\begin{array}{r}4.2 \\
15.8 \\
13.8\end{array}$ & $\begin{array}{r}8.8 \\
4.6 \\
17.1\end{array}$ & $\begin{array}{r}5.0 \\
17.5 \\
18.3\end{array}$ & $\begin{array}{r}8.8 \\
12.5 \\
14.2\end{array}$ & $\begin{array}{l}11.3 \\
17.1 \\
17.5\end{array}$ & $\begin{array}{l}10.8 \\
11.7 \\
15.8\end{array}$ \\
\hline \multicolumn{7}{|c|}{ Target Absent Trials } \\
\hline $\begin{array}{r}5 \\
10 \\
15\end{array}$ & $\begin{array}{l}1.3 \\
0.8 \\
0.4\end{array}$ & $\begin{array}{l}0.8 \\
1.3 \\
1.3\end{array}$ & $\begin{array}{l}0.4 \\
0.4 \\
0.8\end{array}$ & $\begin{array}{l}0.4 \\
0.8 \\
0.8\end{array}$ & $\begin{array}{l}1.3 \\
2.1 \\
1.7\end{array}$ & $\begin{array}{l}2.1 \\
1.7 \\
1.7\end{array}$ \\
\hline
\end{tabular}


it is questionable why, in the present study, the observers were perfectly able to prioritize new over old elements with a preview period of only $50 \mathrm{msec}$. Moreover, the present results show that this ability is critically dependent on whether or not the old elements occur with luminance onset. In the study of Watson and Humphreys (1997) as well as in the study of Humphreys et al. (2004), both old and new elements appeared with luminance onset. It is likely that the failure to obtain a full preview effect with brief intervals is related to the fact that the old elements appeared with luminance onset. With a brief preview, the luminance onsets accompanying the appearance of the old elements might have prevented the new elements from attracting attention. Thus, previous failures to obtain a full preview effect with brief intervals might not have been related to observers' not having enough time to consolidate and inhibit the representation of the old elements but might have occurred merely because the luminance onsets of the old elements prevented attention from being captured by the new elements (Donk $\&$ Theeuwes, 2001). Other studies have shown that if attention is directed to a location in the visual field, visual onsets elsewhere cease to attract attention (Theeuwes, 1991; Yantis \& Jonides, 1990). Something similar might occur in the preview paradigm. If multiple old elements appear with luminance onset, attention might be captured. It might take a certain time interval before attention can be completely disengaged from the locations of the old elements (Duncan et al., 1994). As a consequence, new elements are not capable of capturing attention when they are presented within this interval.

The present findings also challenge the temporal segregation hypothesis of Jiang, Chun, and Marks (2002). Jiang et al. proposed that (part of) the preview effect might be the result of the ability of observers to group subsets of elements on the basis of their temporal separation. They assumed that the preview effect occurs because after segregation of old and new elements, attention may be selectively deployed to the group that contains a target. Even though the temporal segregation hypothesis differs from the visual marking hypothesis in some aspects (see Jiang et al., 2002; Kunar, Humphreys, \& Smith, 2003), both accounts share the idea that a minimal interval is required between the appearances of old and new elements for prioritized selection to develop. The present study shows that, if anything, the minimally required interval is much shorter than that suggested by Jiang et al. Moreover, the present experiment also shows that irrespective of the temporal separation between the appearances of the old and new elements, prioritized selection is critically dependent on whether or not old elements appear with luminance onset. To account for such an effect, Jiang et al. should include the idea that in addition to temporal separation, other forms of grouping play a role. Even though this is a possibility, it is not clear how prioritized selection on the basis of grouping can be ac- complished in such a short interval. Furthermore, if it would be easier to segregate two groups of elements if they have different onset characteristics than if they have the same onset characteristics, then reversing the onset difference, so that old elements appear with onset whereas new elements do not, should still result in a preview benefit. Donk and Theeuwes (2001) showed that this is not the case.

The present results provide strong evidence for the view that prioritized selection of new over old elements is based on an instantaneous process (Donk \& Theeuwes, 2001). In a recent study, Kunar et al. (2003) used a socalled "top-up" preview condition in which green letters appeared for $450 \mathrm{msec}$, followed by their offset for $250 \mathrm{msec}$, and then appeared again $150 \mathrm{msec}$ before blue new letters were added. They demonstrated that search efficiency in the "top-up" preview condition was similar to that in the standard preview condition, showing that the first presentation of old stimuli (during $450 \mathrm{msec}$ ) was important in the generation of the preview effect. Since the history of the old elements was important for the preview benefit, Kunar et al. concluded that an account based on onset capture could not accommodate their results. However, the onset account can easily accommodate the findings of Kunar et al. if it is assumed that in the "top-up" condition, upon their second appearance, old elements no longer attract attention because of inhibition of return (Klein, 1988; Posner \& Cohen, 1984; Pratt \& McAuliffe, 2002). In fact, it is likely that inhibition of return occurred at the locations of the old elements because they were initially presented with abrupt luminance onsets. Note that the present inhibition-of-return account is not meant to be an explanation for the preview effect as such. The finding in the present study that prioritized selection can be obtained with a very brief preview argues against this point of view (see also Pratt $\&$ McAuliffe, 2002).

The present results confirm the onset account of Donk and Theeuwes (2001). According to this account, it is not in principle impossible to prioritize new over old elements with short previews. Prioritized selection is assumed to occur instantaneously, mediated by the luminance onsets of new elements. Yet short previews may result in less effective prioritization if old elements are presented with luminance onset. Luminance onsets at old locations may temporally prevent the luminance onsets of new elements from capturing attention. If old elements are presented without luminance onset (as in the present study), perfect prioritization might be obtained. Indeed, recently, Belopolsky, Theeuwes, and Kramer (in press) demonstrated that even without a preview interval, elements that appear with luminance onset can be perfectly prioritized over elements that appear without luminance onset, again suggesting that the mechanism responsible for this ability is not based on a time-consuming process of inhibition. 


\section{REFERENCES}

Belopolsky, A. V., Theeumes, J., \& Kramer, A. F. (in press). Prioritization by visual transients in search: Evidence against the visual marking account of the preview benefit. Psychonomic Bulletin \& Review.

Donk, M., \& TheEuWes, J. (2001). Visual marking beside the mark: Prioritizing selection by abrupt onsets. Perception \& Psychophysics, 63, 891-900.

Donk, M., \& Theeuwes, J. (2003). Prioritizing selection of new elements: Bottom-up versus top-down control. Perception \& Psychophysics, 65, 1231-1242.

Duncan, J., WARD, R., \& SHAPIRO, K. (1994). Direct measurement of attentional dwell time in human vision. Nature, 369, 313-315.

Humphreys, G. W., Kyllingsb K, S., Watson, D. G., Olivers, C. N. L., LAw, I., \& PAulson, O. B. (2004). Parieto-occipital areas involved in efficient filtering in search: A time course analysis of visual marking using behavioral and functional imaging procedures. Quarterly Journal of Experimental Psychology, 57A, 610-635.

JIANG, Y., CHUN, M. M., \& MARKS, L. E. (2002). Visual marking: Selective attention to asynchronous temporal groups. Journal of Experimental Psychology: Human Perception \& Performance, 28, 717-730.

KLEIN, R. M. (1988). Inhibitory tagging system facilitates visual search. Nature, 334, 430-431.

KunAR, M. A., HumphreYs, G. W., \& SMith, K. J. (2003). History mat- ters: The preview benefit in search is not onset capture. Psychological Science, 14, 181-185.

Posner, M. I., \& Cohen, Y. (1984). Components of visual orienting. In H. Bouma \& D. G. Bouwhuis (Eds.), Attention and performance X: Control of language processes (pp. 531-556). Hillsdale, NJ: Erlbaum.

PRATT, J., \& MCAULIFFE, J. (2002). Inhibition of return in visual marking? The importance of the interstimulus interval and the type of search task. Visual Cognition, 9, 869-888.

THEEUWES, J. (1991). Exogenous and endogenous control of attention: The effect of visual onsets and offsets. Perception \& Psychophysics, 49, 83-90.

Theeuwes, J., Kramer, A. F., \& Atchley, P. (1998). Visual marking of old objects. Psychonomic Bulletin \& Review, 5, 130-134.

WATSON, D. G., \& Humphreys, G. W. (1997). Visual marking: Prioritizing selection for new objects by top-down attention inhibition of old objects. Psychological Review, 104, 90-122.

YANTIS, S., \& JONIDES, J. (1984). Abrupt visual onsets and selective attention: Evidence from visual search. Journal of Experimental Psychology: Human Perception \& Performance, 10, 601-621.

YANTIS, S., \& JONIDES, J. (1990). Abrupt visual onsets and selective attention: Voluntary vs. automatic allocation. Journal of Experimental Psychology: Human Perception \& Performance, 16, 121-134.

(Manuscript received February 6, 2003; revision accepted for publication May 12, 2003.) 